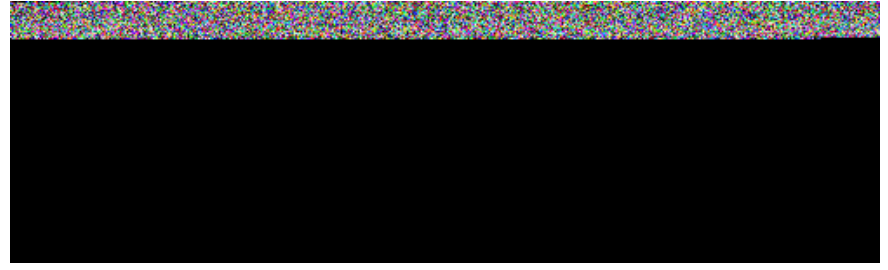

This information is current as of April 26, 2023.

\title{
Effect of Age on GABA+ and Glutathione in a Pediatric Sample
}

M.G. Saleh, A. Papantoni, M. Mikkelsen, S.C.N. Hui, G. Oeltzschner, N.A. Puts, R.A.E. Edden and S. Carnell

AJNR Am J Neuroradiol 2020, 41 (6) 1099-1104 doi: https://doi.org/10.3174/ajnr.A6543

http://www.ajnr.org/content/41/6/1099 


\title{
Effect of Age on GABA+ and Glutathione in a Pediatric Sample
}

\author{
(D) M.G. Saleh, (D) A. Papantoni, (D) M. Mikkelsen, (D) S.C.N. Hui, (D) G. Oeltzschner, (D) N.A. Puts, (D) R.A.E. Edden, and (D) S. Carnell
}

\begin{abstract}
BACKGROUND AND PURPOSE: Gamma-aminobutyric acid (GABA) is the primary inhibitory neurotransmitter in the human brain and is implicated in several neuropathologies. Glutathione is a major antioxidant in the brain and is considered a marker of oxidative stress. Several studies have reported age-related declines in GABA levels in adulthood, but the trajectory of both GABA and glutathione during childhood has not been well explored. The aim of this study is to establish how GABA and glutathione vary with age during early development.
\end{abstract}

MATERIALS AND METHODS: Twenty-three healthy children (5.6-13.9 years of age) were recruited for this study. MR imaging/MR spectroscopy experiments were conducted on a 3T MR scanner. A 27-mL MR spectroscopy voxel was positioned in the frontal lobe. J-difference edited MR spectroscopy was used to spectrally edit GABA and glutathione. Data were analyzed using the Gannet software, and $\mathrm{GABA}+\left(\mathrm{GABA}+\right.$ macromolecules/homocarnosine) and glutathione were quantified using water $\left(\mathrm{GABA}+\mathrm{H}_{2} \mathrm{O}\right.$ and $\left.\mathrm{Glutathione}_{\mathrm{H} 2 \mathrm{O}}\right)$ and $\mathrm{Cr}(\mathrm{GABA}+/ \mathrm{Cr}$ and glutathione/ $\mathrm{Cr}$ ) as concentration references. Also, the relative gray matter contribution to the voxel volume (GM ratio) was estimated from structural images. Pearson correlation coefficients were used to examine the association between age and $\mathrm{GABA}_{\mathrm{H}_{2} \mathrm{O}}$ (and glutathione $\mathrm{H}_{2} \mathrm{O}$ ), between age and $\mathrm{GABA}+/ \mathrm{Cr}$ (and glutathione/ $\mathrm{Cr}$ ), and between age and $\mathrm{GM}_{\text {ratio }}$.

RESULTS: Both GABA $+_{\mathrm{H}_{2} \mathrm{O}}(r=0.63, P=.002)$ and $\mathrm{GABA}+/ \mathrm{Cr}(r=0.48, P=.026)$ significantly correlated with age, whereas glutathione measurements and $\mathrm{GM}_{\text {ratio }}$ did not.

CONCLUSIONS: We demonstrate increases in GABA and no differences in glutathione with age in a healthy pediatric sample. This study provides insight into neuronal maturation in children and may facilitate better understanding of normative behavioral development and the pathophysiology of developmental disorders.

ABBREVIATIONS: $\mathrm{f}_{\mathrm{GM}}=$ gray matter voxel tissue fraction; $\mathrm{f}_{\mathrm{WM}}=$ white matter voxel tissue fraction; $\mathrm{GABA}=$ gamma-aminobutyric acid; $\mathrm{GSH}=$ glutathione; HERMES = Hadamard Encoding and Reconstruction of MEGA-Edited Spectroscopy; MEGA-PRESS = MEscher-GArwood point-resolved spectroscopy sequence; i.u. = institutional units; $\mathrm{GM}_{\text {ratio }}=$ relative $\mathrm{GM}$ contribution to voxel volume; GABA+ $=\mathrm{GABA}$ with macromolecules/homocarnosine

$\mathrm{n}$ vivo MR spectroscopy is a noninvasive tool for measuring brain metabolite levels to investigate both healthy and pathologic physiology. ${ }^{1,2}$ The main inhibitory neurotransmitter gamma-aminobutyric acid (GABA) and the primary antioxidant glutathione (GSH) are of considerable interest due to their critical roles in governing neuronal activity and protection against oxidative stress.

Received January 27, 2020; accepted after revision March 23.

From the Russell H. Morgan Department of Radiology and Radiological Science (M.G.S., M.M., S.C.N.H., G.O., N.A.P., R.A.E.E.); and Department of Psychiatry and Behavioral Sciences, Division of Child and Adolescent Psychiatry (A.P., S.C.), The Johns Hopkins University School of Medicine, Baltimore, Maryland; F.M. Kirby Research Center for Functional Brain Imaging (M.G.S., M.M., S.C.N.H., G.O., N.A.P. R.A.E.E.), Kennedy Krieger Institute, Baltimore, Maryland; and Department of Forensic and Neurodevelopmental Sciences (N.A.P.), Institute of Psychiatry, Psychology and Neuroscience, King's College, London, UK.

This work was supported by National Institutes of Health grants P41 EB015909 R01 016089 R01 EB023693, K99AG062230, R01DK113286, UG3OD023313, R00DK088360, and a Johns Hopkins Discovery Award.
However, in vivo measurement of GABA and GSH is challenging due to substantial signal overlap with creatine $(\mathrm{Cr}) .^{3}$ Hadamard Encoding and Reconstruction of MEGA-Edited Spectroscopy (HERMES) ${ }^{4}$ is a novel J-difference editing method that selectively detects multiple metabolites simultaneously and removes overlapping signals, offering substantial scan time reductions over previously used MEscher-GArwood point-resolved spectroscopy sequence (MEGA-PRESS), ${ }^{5}$ which is limited to single-metabolite editing. In the present study, we use J-difference editing methods

Please address correspondence to Muhammad G. Saleh, PhD, Russell H. Morgan Department of Radiology and Radiological Science, The Johns Hopkins University School of Medicine, 600 N Wolfe St, Baltimore, MD 21287; e-mail: msaleh10@jhmi.edu

-- Indicates open access to non-subscribers at www.ajnr.org

http://dx.doi.org/10.3174/ajnr.A6543 
to measure age-related changes in GABA and GSH in vivo in a healthy pediatric sample.

GABA is critical to brain function throughout the life span, ${ }^{2}$ playing a vital role in inhibitory control. However, studies of age-related differences are limited. Most studies examining the relationship between GABA and age have focused on late development to adulthood. Some studies have demonstrated increases in GABA with age from late childhood to late adulthood, ${ }^{6-8}$ and others observed decreases in GABA from late adolescence to late adulthood..$^{9-11}$ Also, a small number of cross-sectional studies have compared GABA between 2 age groups. Silveri et $\mathrm{al}^{12}$ found lower GABA levels in adolescents relative to emerging adults; Simmonite et $\mathrm{al}^{13}$ demonstrated higher GABA levels in younger participants relative to older participants. Thus, prior work seems to suggest an increase in GABA through development, followed by a period of relative stability, and then a decline. However, we have limited understanding of how GABA levels vary in early life. This information is of particular interest given the important role of GABA in cortical pruning and plasticity in early development. ${ }^{14}$

GSH is a critical element in the natural defense of the cell against damaging reactive oxygen species. Oxidative stress and GSH have been implicated in a range of neurologic and psychiatric conditions, including neurodevelopmental and neurodeg-

Sample distribution of the pediatric cohort, voxel tissue composition, and metabolite concentrations ${ }^{a}$

\begin{tabular}{ll}
\hline \multicolumn{1}{c}{ Parameters } & \\
\hline No. & 23 \\
Sex (male/female) & $12 / 11$ \\
Age (yr) & $5.6-13.9 ; 10.2 \pm 2.5$ \\
Male & $5.6-13.9 ; 9.81 \pm 3.01$ \\
Female & $8.1-13.1 ; 10.61 \pm 1.76$ \\
Race (No.) & \\
Black/African-American & 4 \\
White & 16 \\
$>1$ race & 3 \\
Voxel tissue composition & \\
Gray matter (\%) & $51.7 \pm 4.8$ \\
White matter (\%) & $31.0 \pm 3.5$ \\
GM ${ }_{\text {ratio }}(\%)$ & $62.5 \pm 3.8$ \\
Metabolite levels & \\
GABA+H2O (i.u.) & $2.70-4.37 ; 3.35 \pm 0.48$ \\
GABA+/Cr & $0.073-0.120 ; 0.102 \pm 0.011$ \\
GSH ${ }_{\text {H2O (i.u.) }}$ & $1.07-1.92 ; 1.50 \pm 0.24$ \\
GSH/Cr & $0.036-0.058 ; 0.05 \pm 0.006$ \\
\hline
\end{tabular}

${ }^{a}$ Data are minimum-maximum; mean $\pm \mathrm{SD}$.

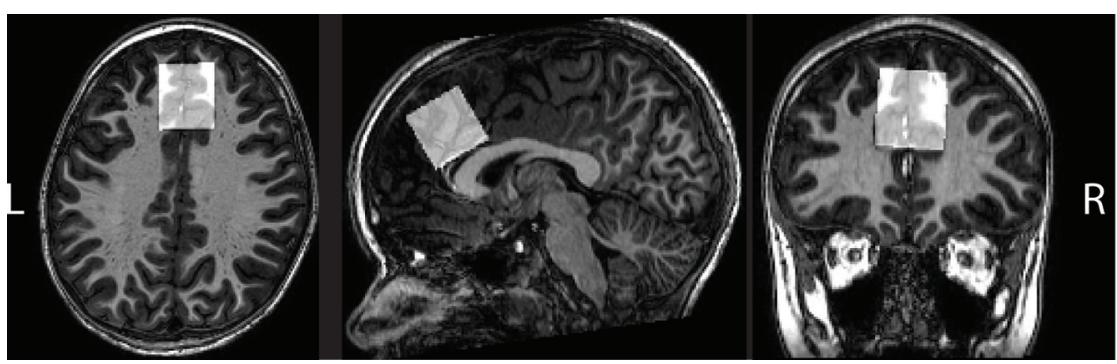

FIG 1. Structural images showing voxel localized in the frontal lobe on the midline above the genu of the corpus callosum, to include the anterior cingulate cortex. enerative disorders. ${ }^{15}$ It has previously been shown in healthy individuals that plasma levels of GSH decline with age. ${ }^{16}$ However, plasma measurements do not directly reflect brain levels of GSH, which are most relevant to psychiatric and neurologic pathologies. ${ }^{17}$ Only 1 study reported a relationship between MR spectroscopy measures of GSH and age; GSH levels in the occipital cortex in healthy young participants were higher compared with healthy elderly participants. ${ }^{18}$

Because an understanding of normative neuronal maturation is essential to understand the biologic basis of normative behavioral development (eg, development of inhibitory control) as well as to investigate neurodevelopmental disorders, the aim of this study was to use MR spectroscopy to establish how GABA and GSH vary with age during early development. Prior work suggests that GABA increases in early adolescence and decreases in late adulthood, whereas plasma measurements of GSH do not significantly vary from childhood to adulthood (0-40 years of age). We therefore hypothesized that GABA increases and that GSH does not change from early childhood to early adolescence.

\section{MATERIALS AND METHODS \\ Subjects}

A total of 23 children were recruited for this study (Table). The study protocol and consent forms were approved by the local institutional review board (Johns Hopkins Medicine). Written parental consent was obtained for all participants. Additionally, written assent was obtained from children able to make an independent decision to participate (older than 8 years of age).

\section{Acquisition Protocol}

MR imaging/MR spectroscopy experiments were conducted on a Philips 3T MR imaging scanner (Philips Healthcare, Eindhoven, Netherlands) using a 32-channel head coil. After a high-resolution $\left(1 \mathrm{~mm}^{3}\right)$ whole-brain 3D MPRAGE acquisition, the MR spectroscopy voxel was positioned in the frontal lobe on the midline above the genu of the corpus callosum, to include the anterior cingulate cortex, as shown in Fig 1. Subjects were scanned using the HERMES sequence for the simultaneous measurement of GABA with macromolecules and homocarnosine $(\mathrm{GABA}+)$ at $3.0 \mathrm{ppm}$ and GSH at $2.95 \mathrm{ppm}$. Briefly, the HERMES sequence consists of 4 subexperiments: A) a dual-lobe editing pulse $\left(\mathrm{ON}_{\mathrm{GABA}}\right.$ at $1.9 \mathrm{ppm}$; $\mathrm{ON}_{\mathrm{GSH}}$ at $\left.4.56 \mathrm{ppm}\right)$; B) a single-lobe editing pulse $\left.\left(\mathrm{ON}_{\mathrm{GABA}}\right) ; \mathrm{C}\right) \mathrm{a}$ single-lobe editing pulse $\left(\mathrm{ON}_{\mathrm{GSH}}\right)$; and $\left.\mathrm{D}\right)$ a single-lobe editing pulse at $7.5 \mathrm{ppm}\left(\mathrm{OFF}_{\mathrm{GABA} / \mathrm{GSH}}\right)$. GABA+- and GSH-edited spectra were generated using the Hadamard combinations $\mathrm{A}+\mathrm{B}-\mathrm{C}-\mathrm{D}$ and $\mathrm{A}-\mathrm{B}+\mathrm{C}-\mathrm{D}$, respectively. Due to technical error, HERMES was not run for 3 subjects in whom the MEGA-PRESS sequence for detection of $\mathrm{GABA}+$ was performed instead $\left(\mathrm{ON}_{\mathrm{GABA}}\right.$ at $1.9 \mathrm{ppm}$ and $\mathrm{OFF}_{\mathrm{GABA}}$ at $7.5 \mathrm{ppm}$ ). MR spectroscopy data were acquired with the following acquisition parameters: $30 \times 30 \times 30 \mathrm{~mm}^{3}$ voxel size, TE/ $\mathrm{TR}=80 / 2000 \mathrm{~ms}, \quad 20-\mathrm{ms}$ editing pulse duration, 2048 data points, 2- 

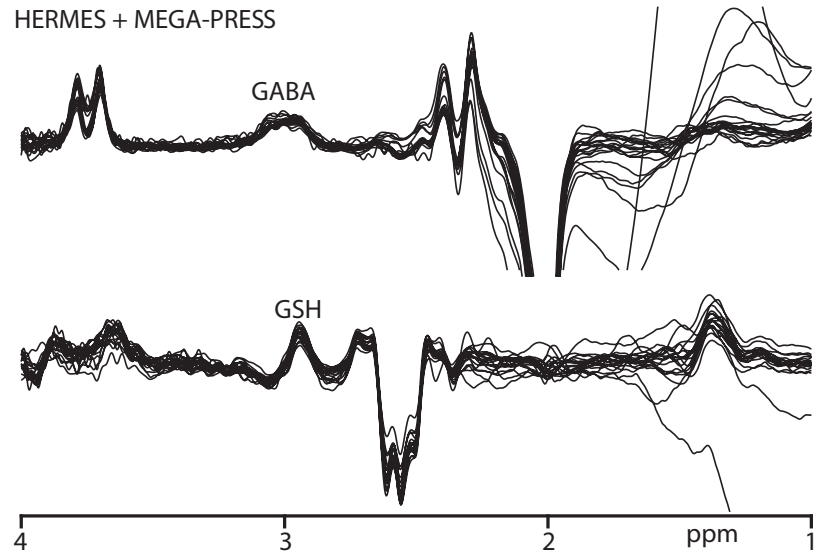

FIG 2. GABA+- and GSH-edited spectra from participants with a fit error of $<15 \%$. GABA+-edited spectra are acquired using both HERMES and MEGA-PRESS sequences.
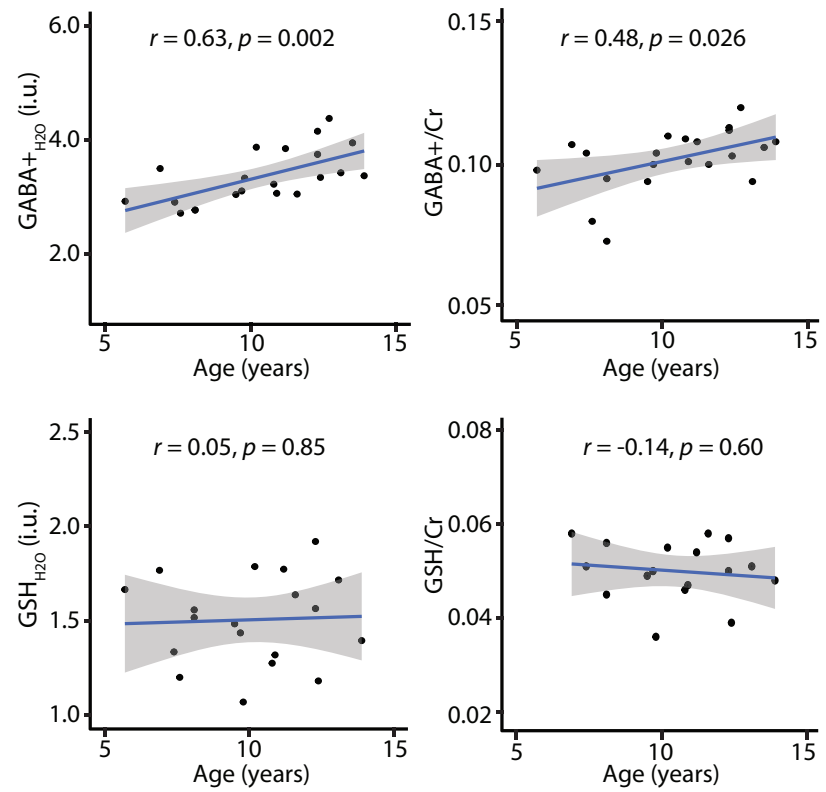

FIG 3. GABA+ and GSH correlations with age. Significant correlations are observed between GABA+ and age, whereas GSH does not significantly correlate with age. $r$ indicates the Pearson correlation coefficient.

$\mathrm{kHz}$ spectral width, 304 transients, and variable power and optimized relaxation delays (VAPOR) water suppression. ${ }^{19}$ Inter-leaved water referencing was applied to minimize the effects of magnetic field $\left(\mathrm{B}_{0}\right)$ drift during data acquisition ${ }^{20}$ and as concentration reference data for each subject.

\section{Data Processing}

Data were analyzed using Gannet software (Version 3.1). ${ }^{21}$ A modified multistep frequency-and-phase correction was applied to the data to reduce subtraction artifacts, ${ }^{22}$ followed by a $3-\mathrm{Hz}$ exponential filter and zero-padding by a factor of 16 . Finally, the fully-processed HERMES and MEGA-PRESS subspectra were combined to generate GABA+- and GSH-edited spectra (HERMES only). Hankel Singular Value Decomposition water filtering was applied to remove the residual water signal. ${ }^{23}$ The GABA+, GSH, and 3.0ppm $\mathrm{Cr}$ (from $\mathrm{OFF}_{\mathrm{GABA} / \mathrm{GSH}}$ and $\mathrm{OFF}_{\mathrm{GABA}}$, respectively) signals were modeled to calculate $\mathrm{GABA}+/ \mathrm{Cr}$ and $\mathrm{GSH} / \mathrm{Cr}$ integral ratios. MPRAGE images were segmented by using SPM12 (http://www.fil. ion.ucl.ac.uk/spm/software/spm12) ${ }^{24}$ to calculate gray matter $\left(\mathrm{f}_{\mathrm{GM}}\right)$, white matter $\left(f_{\mathrm{WM}}\right)$, and CSF voxel tissue fractions. Absolute concentrations $\left(\mathrm{GABA}+{ }_{\mathrm{H} 2 \mathrm{O}}\right.$ and $\left.\mathrm{GSH}_{\mathrm{H} 2 \mathrm{O}}\right)$ were also calculated in institutional units (i.u.), correcting for tissue-dependent signal attenuation. ${ }^{25}$ The gray matter ratio $\left(\mathrm{GM}_{\text {ratio }}=\mathrm{f}_{\mathrm{GM}} / \mathrm{f}_{\mathrm{GM}}+\mathrm{f}_{\mathrm{WM}}\right)$ was calculated using the tissue fractions for correlational analysis, as described below. To assess data quality, we used $\mathrm{B}_{0}$ drift and water signal linewidth at full width at half maximum. The $\mathrm{Cr}$ signal at $3 \mathrm{ppm}$ and the water signal at $4.68 \mathrm{ppm}$ were used to estimate $\mathrm{B}_{0}$ drift in the in vivo HERMES and MEGA-PRESS data, respectively, before frequency/phase alignment. Also, the GABA+ and GSH fit errors (defined as the ratio of the SD of the fit residual to the amplitude of the modeled peak) from Gannet were used for assessing modeling errors. ${ }^{21}$

\section{Analysis}

The mean and SD of all fit errors (combining GABA and GSH fit errors) were calculated, and subsequently determined that a value of $15 \%$ was approximately the 95 th percentile (ie, $\sim 2$ SDs above the mean); therefore, we used this as a threshold for data rejection before statistical analysis. Pearson correlation coefficients $(r)$ were calculated to examine the association between age and GABA and between age and GSH, with separate analyses for water$\left(\mathrm{GABA}+{ }_{\mathrm{H} 2 \mathrm{O}}\right.$ and $\left.\mathrm{GSH}_{\mathrm{H} 2 \mathrm{O}}\right)$ and $\mathrm{Cr}$-referenced $(\mathrm{GABA}+/ \mathrm{Cr}$ and $\mathrm{GSH} / \mathrm{Cr}$ ) measurements, and between age and the $\mathrm{GM}_{\text {ratio }}$. Subsequently, correlations of $\mathrm{GABA}+{ }_{\mathrm{H} 2 \mathrm{O}}$ (and $\mathrm{GABA}+/ \mathrm{Cr}$ ) with age were calculated in male and female participants separately. Outliers were identified using the $\operatorname{Cook}^{26}$ distance estimates, excluding values higher than $4 /(n-2)$, where $n$ is the sample size. A $P$ value $<.05$ was considered statistically significant. Statistical analyses were conducted in $\mathrm{R}$ statistical and computing software (http://www.r-project.org). ${ }^{27}$ Unless otherwise stated, values are presented as mean or mean $\pm \mathrm{SD}$.

\section{RESULTS}

All participants recruited for the study successfully completed scanning. $\mathrm{B}_{0}$ drift during the 10 -minute edited MR spectroscopy acquisitions was $2.41 \pm 0.91 \mathrm{~Hz}$, and the water linewidth was $8.22 \pm$ $0.49 \mathrm{~Hz}$, respectively, indicating good frequency stability and $\mathrm{B}_{0}$ homogeneity. One GABA + and 2 GSH measurements were removed due to fit errors exceeding 15\%. The remaining data yielded low fit errors (GABA+/GSH: $6.03 \pm 1.85 / 8.80 \pm 1.51 \%$ ). Figure 2 shows the edited difference spectra for subjects with fit errors $<15 \%$.

$\mathrm{GM}_{\text {ratio }}, \mathrm{GABA}+$, and GSH measurements are reported in the Table. Correlations between $\mathrm{GABA}{ }_{\mathrm{H} 2 \mathrm{O}}$ (and $\mathrm{GSH}_{\mathrm{H} 2 \mathrm{O}}$ ) and age, and GABA+/Cr (and GSH/Cr) with age are shown in Fig 3. Significant correlations were observed between $\mathrm{GABA}+{ }_{\mathrm{H} 2 \mathrm{O}}$ and age $(r=0.63, P=.002)$, and between $\mathrm{GABA}+/ \mathrm{Cr}$ and age $(r=0.48, P=.026)$. Neither GSH measurements nor $\mathrm{GM}_{\text {ratio }}$ significantly correlated with age.

When we separated results by sex, correlations of GABA $+_{\mathrm{H} 2 \mathrm{O}}$ to age were observed in both male and female participants (male/ female ratio: $r=0.60 / 0.71, \quad P=.07 / .01)$; however, only the 
correlation in female participants was significant. Also, nonsignificant correlations of $\mathrm{GABA}+/ \mathrm{Cr}$ to age were observed in both male and female participants (male/female ratio: $r=0.50 / 0.58$, $P=.15 / .06)$.

\section{DISCUSSION}

Inhibitory dysfunction and oxidative stress are widely implicated disease mechanisms in young children and adolescents, including in autism, ${ }^{28,29}$ depression, ${ }^{30}$ and Tourette syndrome. $^{31,32}$ To understand the involvement of GABA and GSH in inhibitory dysfunction and oxidative stress with respect to normal and pathologic development, one must establish baseline distributions of these metabolites in typically developing children. To our knowledge, this is the first study investigating age-related effects on GABA and GSH levels in a healthy young pediatric sample (ranging from $\sim 5$ to $\sim 14$ years of age). Our findings demonstrate significant increases in GABA + with increasing age, whereas GSH measurements show no association with age.

The age-related increase in GABA + we report in this study is consistent with previous studies that used MEGA-PRESS to assess GABA + in healthy adolescents. ${ }^{6,12}$ Studies have linked GABA with important functions in the developing brain, including myelination and synaptic pruning. ${ }^{33,34}$ Myelination begins during gestation and extends beyond adolescence, progressing from parietal to frontal regions. ${ }^{35,36}$ Besides de novo myelination, existing myelin can undergo remodeling-such as a change in myelin sheath length/thickness or internode length - to restore myelination patterns or facilitate neuronal activity during development or learning. ${ }^{37,38}$ Oligodendrocyte precursor cells have the potential to proliferate, differentiate, and form new myelin-forming oligodendrocytes. ${ }^{38}$ Hamilton et $\mathrm{al}^{39}$ recently demonstrated in mice that endogenous release of $\mathrm{GABA}$, which acts on $\mathrm{GABA}_{\mathrm{A}}$ receptors of oligodendrocyte precursor cells, reduces the number of oligodendrocyte precursor cells and oligodendrocytes produced, thus, the control of myelination and myelin internode length. Because our study shows insignificant correlation of $\mathrm{GM}_{\text {ratio }}$ with age, it is possible that increasing GABA+ levels with age may support remodeling or regulation of existing myelin. Synaptic pruning is an important process that eliminates unnecessary synaptic connections to increase the efficiency of neuronal transmission. $\mathrm{GABA}_{\mathrm{A}}$ receptors in the dendritic spines of mice trigger synaptic pruning at puberty, improving spatial relearning. ${ }^{34}$ Thus, increases in GABA + with age may facilitate synaptic pruning to allow the development of new cognitive abilities during adolescence. Both myelin remodeling and synaptic pruning may have structural and functional implications. Structural implications take place at the neuronal level and cannot be detected using macroscopic morphometry measurements, whereas functional implications can be inferred by correlations with relevant measures of cognition (eg, impulsivity, response inhibition, working memory). ${ }^{7,12}$

In this study, the overall positive correlation of GABA+ with age was not sex-specific, with both males and females showing a positive correlation between GABA+ and age (albeit with a loss of power associated with splitting the data). In the present study, female participants' ages overlapped with the postpubertal period, which may impact GABA+, ${ }^{40}$ and were not controlled for in our analyses. The absence of consistently significant correlation values is likely due to the small sample size. The present findings would ideally be replicated in a larger sample, controlling for menstrual status in female participants.

There were no GSH differences with age, consistent with a large study involving 176 healthy subjects that demonstrated no statistical differences in plasma GSH among 3 age groups (age: 2-11, 12-24, and $25-40$ years). ${ }^{16}$ These findings suggest that GSH synthesis remains stable in young children and early adolescents, providing effective protection against reactive oxygen species. Furthermore, our results suggest that the trajectory of GSH is consistent between brain and plasma. Glutathione also exists in an oxidized form, which is 40-100 times lower than the reduced form (GSH) in a healthy brain. ${ }^{15,16}$ Although levels of GSH represent the ability of the brain to defend against reactive oxygen species, the ratio of GSH/oxidized glutathione would be a useful indicator of age-related cellular redox status. However, the current state of MR spectroscopy lacks the sensitivity to detect oxidized glutathione in vivo. ${ }^{41}$

The acquisition protocol for this study has limitations. First, GABA and GSH have low signal amplitudes, necessitating the use of a large volume of interest. Enhancements in hardware and pulse sequences ${ }^{42,43}$ might enable the use of smaller VOIs and more efficient region-specific analyses of brain GABA and GSH changes. Second, the detected GABA+ signal contains a significant contribution from macromolecules and homocarnosine. ${ }^{44}$ It is possible that the presence of a correlation was due to an increase in the concentration of macromolecules or homocarnosine as a function of age, as suggested by a number of studies. ${ }^{45-49}$ Further studies applying metabolite nulling ${ }^{47}$ or macromolecule-suppressed editing $^{44,50}$ are required to directly address this question. Third, subject motion is a concern when scanning children, causing data acquisition at an unintended location and reduced data quality, ${ }^{51}$ and additional concerns for edited measurements. Thus, macromolecule-suppressed editing (the most motion-sensitive technique) was not applied in this cohort. This study did apply real-time frequency correction, ${ }^{20}$ resulting in relatively good $\mathrm{B}_{0}$ stability $(\sim 3 \mathrm{~Hz})$ and postprocessing frequency corrections to minimize subtraction artifacts. Incorporation of motion-and-shim-correction methods ${ }^{52-55}$ would ensure improved robustness of measurements to motion. Fourth, the present study focused on 1 brain region. Results may not be uniform across all brain regions, as demonstrated in adults. ${ }^{56}$ Finally, the study uses a cross-sectional design, and future studies should use longitudinal data to explicitly investigate agerelated changes in GABA and GSH across the brain.

\section{CONCLUSIONS}

To our knowledge, this is the first study to demonstrate that $\mathrm{GABA}+{ }_{\mathrm{H} 2 \mathrm{O}}$ and $\mathrm{GABA}+/ \mathrm{Cr}$ increases with age, while $\mathrm{GSH}$ does not in a healthy pediatric sample. Given the increasing use of MR spectroscopy to measure both GABA and GSH to investigate both normal and abnormal brain physiology, normative studies of age-related differences in GABA and GSH are needed.

Disclosures: Afroditi Papantoni-UNRELATED: Employment: Johns Hopkins University. Georg Oeltzschner-RELATED: Grant: National Institute on Aging, Comments: K99AG062230.* Nicolaas A. Puts—RELATED: Grant: National Institute of Mental Health, Comments: Salary paid from this grant.* Richard A. E. Edden-RELATED: Grant: National Institutes of Health, Comments: P41 EB015909 R01 016089 R01 EB023693.* Susan Carnell—RELATED: Grant: National Institutes 
of Health, Comments: R00DK088360, R01DK113286 UG3OD023313 and the Johns Hopkins Discovery award.* ${ }^{*}$ Money paid to the institution.

\section{REFERENCES}

1. Currie S, Hadjivassiliou M, Craven IJ, et al. Magnetic resonance spectroscopy of the brain. Postgrad Med J 2013;89:94-106 CrossRef Medline

2. Rae CD. A guide to the metabolic pathways and function of metabolites observed in human brain $1 \mathrm{H}$ magnetic resonance spectra. Neurochem Res 2014;39:1-36 CrossRef Medline

3. Harris AD, Saleh MG, Edden RA. Edited $1 \mathrm{H}$ magnetic resonance spectroscopy in vivo: methods and metabolites. Magn Reson Med 2017;77:1377-89 CrossRef Medline

4. Saleh MG, Oeltzschner G, Chan KL, et al. Simultaneous edited MRS of GABA and glutathione. Neuroimage 2016;15:576-82 CrossRef Medline

5. Mescher M, Merkle H, Kirsch J, et al. Simultaneous in vivo spectral editing and water suppression. NMR Biomed 1998;11:26672 CrossRef Medline

6. Gaetz W, Bloy L, Wang D, et al. GABA estimation in the brains of children on the autism spectrum: measurement precision and regional cortical variation. Neuroimage 2014;86:1-9 CrossRef Medline

7. Ghisleni C, Bollmann S, Poil S-S, et al. Subcortical glutamate mediates the reduction of short-range functional connectivity with age in a developmental cohort. J Neurosci 2015;35:8433-41 CrossRef Medline

8. Port RG, Gaetz W, Bloy L, et al. Exploring the relationship between cortical GABA concentrations, auditory gamma-band responses and development in ASD: evidence for an altered maturational trajectory in ASD. Autism Res 2017;10:593-607 CrossRef Medline

9. Gao F, Edden RA, Li M, et al. Edited magnetic resonance spectroscopy detects an age-related decline in brain GABA levels. Neuroimage 2013;78:75-82 CrossRef Medline

10. Porges EC, Woods AJ, Edden RA, et al. Frontal gamma-aminobutyric acid concentrations are associated with cognitive performance in older adults. Biol Psychiatry Cogn Neurosci Neuroimaging 2017;2:3844 CrossRef Medline

11. Marenco S, Savostyanova AA, van der Veen JW, et al. Genetic modulation of GABA levels in the anterior cingulate cortex by GAD1 and COMT. Neuropsychopharmacology 2010;35:1708-17 CrossRef Medline

12. Silveri MM, Sneider JT, Crowley DJ, et al. Frontal lobe $\gamma$-aminobutyric acid levels during adolescence: associations with impulsivity and response inhibition. Biol Psychiatry 2013;74:296-304 CrossRef Medline

13. Simmonite M, Carp J, Foerster BR, et al. Age-related declines in occipital GABA are associated with reduced fluid processing ability. Acad Radiol 2019;26:1053-61 CrossRef Medline

14. Wu X, Fu Y, Knott G, et al. GABA signaling promotes synapse elimination and axon pruning in developing cortical inhibitory interneurons. J Neurosci 2012;32:331-43 CrossRef Medline

15. Rae CD, Williams SR. Glutathione in the human brain: review of its roles and measurement by magnetic resonance spectroscopy. Anal Biochem 2017;529:127-43 CrossRef Medline

16. Erden-Inal M, Sunal E, Kanbak G. Age-related changes in the glutathione redox system. Cell Biochem Funct 2002;20:61-66 CrossRef Medline

17. Smaga I, Niedzielska E, Gawlik M, et al. Oxidative stress as an etiological factor and a potential treatment target of psychiatric disorders, Part 2: depression, anxiety, schizophrenia and autism. Pharmacol Rep 2015;67:569-80 CrossRef Medline

18. Emir UE, Raatz S, McPherson S, et al. Noninvasive quantification of ascorbate and glutathione concentration in the elderly human brain. NMR Biomed 2011;24:888-94 CrossRef Medline

19. Tkác I, Starcuk Z, Choi IY, et al. In vivo 1 H NMR spectroscopy of rat brain at $1 \mathrm{~ms}$ echo time. Magn Reson Med 1999;41:649-56 CrossRef Medline
20. Edden RA, Oeltzschner G, Harris AD, et al. Prospective frequency correction for macromolecule-suppressed GABA editing at 3T. $J$ Magn Reson Imaging 2016;44:1474-82 CrossRef Medline

21. Edden RA, Puts NA, Harris AD, et al. Gannet: a batch-processing tool for the quantitative analysis of gamma-aminobutyric acidedited MR spectroscopy spectra. J Magn Reson Imaging 2014;40:144552 CrossRef Medline

22. Mikkelsen M, Saleh MG, Near J, et al. Frequency and phase correction for multiplexed edited MRS of GABA and glutathione. Magn Reson Med 2018;80:21-28 CrossRef Medline

23. Barkhuijsen $H$, De Beer R, van Ormondt D. Improved algorithm for noniterative time-domain model fitting to exponentially damped magnetic resonance signals. Journal of Magnetic Resonance (1969) 1987;73:553-57 CrossRef

24. Ashburner J, Friston KJ. Unified segmentation. Neuroimage 2005;26:83951 CrossRef Medline

25. Gasparovic C, Song T, Devier D, et al. Use of tissue water as a concentration reference for proton spectroscopic imaging. Magn Reson Med 2006;55:1219-26 CrossRef Medline

26. Cook RD. Influential observations in linear regression. Journal of the American Statistical Association 1979;74:169-74 CrossRef

27. R Project for Statistical Computing. https://www.R-project.org. Accessed July 19, 2019

28. Drenthen GS, Barendse EM, Aldenkamp AP, et al. Altered neurotransmitter metabolism in adolescents with high-functioning autism. Psychiatry Res Neuroimaging 2016;256:44-49 CrossRef Medline

29. Puts NA, Wodka EL, Harris AD, et al. Reduced GABA and altered somatosensory function in children with autism spectrum disorder. Autism Res 2017;10:608-69 CrossRef Medline

30. Freed RD, Hollenhorst CN, Weiduschat N, et al. A pilot study of cortical glutathione in youth with depression. Psychiatry Res Neuroimaging 2017;270:54-60 CrossRef Medline

31. Puts NA, Harris AD, Crocetti D, et al. Reduced GABAergic inhibition and abnormal sensory symptoms in children with Tourette syndrome. J Neurophysiol 2015;114:808-17 CrossRef Medline

32. Frustaci A, Neri M, Cesario A, et al. Oxidative stress-related biomarkers in autism: systematic review and meta-analyses. Free Radic Biol Med 2012;52:2128-41 CrossRef Medline

33. Vélez-Fort M, Audinat E, Angulo MC. Central role of GABA in neuron-glia interactions. Neuroscientist 2012;18:237-50 CrossRef Medline

34. Afroz S, Parato J, Shen $\mathrm{H}$, et al. Synaptic pruning in the female hippocampus is triggered at puberty by extrasynaptic GABAA receptors on dendritic spines. Elife 2016;5 CrossRef Medline

35. Sowell ER, Thompson PM, Toga AW. Mapping changes in the human cortex throughout the span of life. Neuroscientist 2004;10:37292 CrossRef Medline

36. Gogtay N, Giedd JN, Lusk L, et al. Dynamic mapping of human cortical development during childhood through early adulthood. Proc Natl Acad Sci U S A 2004;101:8174-79 CrossRef Medline

37. Williamson JM, Lyons DA. Myelin dynamics throughout life: an ever-changing landscape? Front Cell Neurosci 2018;12:424 CrossRef Medline

38. Sampaio-Baptista C, Johansen-Berg H. White matter plasticity in the adult brain. Neuron 2017;96:1239-51 CrossRef Medline

39. Hamilton NB, Clarke LE, Arancibia-Carcamo IL, et al. Endogenous GABA controls oligodendrocyte lineage cell number, myelination, and CNS internode length. Glia 2017;65:309-21 CrossRef Medline

40. Epperson CN, Haga K, Mason GF, et al. Cortical $\gamma$-aminobutyric acid levels across the menstrual cycle in healthy women and those with premenstrual dysphoric disorder: a proton magnetic resonance spectroscopy study. Arch Gen Psychiatry 2002;59:851-58 CrossRef Medline

41. Satoh T, Yoshioka Y. Contribution of reduced and oxidized glutathione to signals detected by magnetic resonance spectroscopy as indicators of local brain redox state. Neurosci Res 2006;55:34-39 CrossRef Medline 
42. Bogner W, Hangel G, Esmaeili M, et al. 1D-spectral editing and 2D multispectral in vivo ${ }^{1} \mathrm{H}$-MRS and ${ }^{1} \mathrm{H}$-MRSI: methods and applications. Anal Biochem 2017;529:48-64 CrossRef Medline

43. Saleh MG, Mikkelsen M, Oeltzschner G, et al. Simultaneous editing of GABA and glutathione at 7T using semi-LASER localization. Magn Reson Med 2018;80:474-77 CrossRef Medline

44. Deelchand DK, Marjańska M, Henry PG, et al. MEGA-PRESS of GABA+: influences of acquisition parameters. NMR Biomed 2019 Oct 28. [Epub ahead of print] CrossRef Medline

45. Aufhaus E, Weber-Fahr W, Sack M, et al. Absence of changes in GABA concentrations with age and gender in the human anterior cingulate cortex: a MEGA-PRESS study with symmetric editing pulse frequencies for macromolecule suppression. Magn Reson Med 2013;69:317-20 CrossRef Medline

46. Rowland LM, Krause BW, Wijtenburg SA, et al. Medial frontal GABA is lower in older schizophrenia: a MEGA-PRESS with macromolecule suppression study. Mol Psychiatry 2016;21:198-204 CrossRef Medline

47. Hofmann L, Slotboom J, Boesch C, et al. Characterization of the macromolecule baseline in localized $1 \mathrm{H}-\mathrm{MR}$ spectra of human brain. Magn Reson Med 2001;46:855-63 CrossRef Medline

48. Tkácõ I, Rao R, Georgieff $\mathrm{MK}$, et al. Developmental and regional changes in the neurochemical profile of the rat brain determined by in vivo 1H NMR spectroscopy. Magn Reson Med 2003;50:24-32 CrossRef Medline

49. Kreis R, Hofmann L, Kuhlmann B, et al. Brain metabolite composition during early human brain development as measured by quantitative in vivo $\mathbf{1} \mathbf{H}$ magnetic resonance spectroscopy. Magn Reson Med 2002;48:949-58 CrossRef Medline

50. Henry PG, Dautry C, Hantraye P, et al. Brain GABA editing without macromolecule contamination. Magn Reson Med 2001;45:517-20 CrossRef Medline

51. Hess AT, van der Kouwe AJ, Mbugua KK, et al. Quality of $\mathbf{1 8 6}$ child brain spectra using motion and $\mathrm{B} 0$ shim navigated single voxel spectroscopy. J Magn Reson Imaging 2014;40:958-65 CrossRef Medline

52. Saleh MG, Alhamud A, Near J, et al. Volumetric navigated MEGASPECIAL for real-time motion and shim corrected GABA editing. NMR Biomed 2016;29:248-55 CrossRef Medline

53. Saleh MG, Near J, Alhamud A, et al. Reproducibility of macromolecule suppressed GABA measurement using motion and shim navigated MEGA-SPECIAL with LCModel, jMRUI and GANNET. MAGMA 2016;29:863-74 CrossRef Medline

54. Bogner W, Gagoski B, Hess AT, et al. 3D GABA imaging with realtime motion correction, shim update and reacquisition of adiabatic spiral MRSI. Neuroimage 2014;103:290-302 CrossRef Medline

55. Hnilicová $P$, Povazõan $M$, Strasser $B$, et al. Spatial variability and reproducibility of GABA-edited MEGA-LASER 3D-MRSI in the brain at 3 T. NMR Biomed 2016;29:1656-65 CrossRef Medline

56. Hermans L, Leunissen I, Maes C, et al. The aging brain and changes in GABA concentrations. In: Proceedings of the 12th National Congress of the Belgian Society for Neuroscience, Brussels, Belgium. May 24, 2019 